\title{
Sooner than later: a little effort may avert postpartum haemorrhage in patients with acute hepatitis $\mathbf{E}$
}

\author{
Neha Thakur, Ruchi Kishore*, Mitali Tuwani
}

Department of Obstetrics and Gynecology, Pt. Jawaharlal Nehru Medical College Raipur, Chhattisgarh, India

Received: 10 August 2021

Revised: 26 August 2021

Accepted: 27 August 2021

\section{*Correspondence:}

Dr. Ruchi Kishore,

E-mail: ashishkumarruchi@yahoo.com

Copyright: (C) the author(s), publisher and licensee Medip Academy. This is an open-access article distributed under the terms of the Creative Commons Attribution Non-Commercial License, which permits unrestricted non-commercial use, distribution, and reproduction in any medium, provided the original work is properly cited.

\section{ABSTRACT}

Background: The incidence of postpartum hemorrhage (PPH) in pregnancies with hepatitis E varies from 14-42\%. Management of labor and PPH in these women with acute liver injury makes it a real obstetric challenge due to associated coagulopathies and contraindication for many drugs. Prophylactic insertion of condom balloon tamponade along with active management of the third stage of labour (AMTSL) prevent primary PPH in these women. Simultaneous use of injection tranexemic acid further gives reliable results. The present study was conducted to study the effectiveness of condom balloon tamponade in preventing PPH in pregnant women with acute hepatitis E in labor. Methods: The present study was conducted in the Department of Obstetrics and Gynecology, Pt. Jawaharlal Nehru Medical (JNM) College and associated Dr. Bhim Rao Ambedkar Memorial (BRAM) Hospital, Raipur, Chhattisgarh over period of two year from September 2018 to September 2020.

Results: During the study period 32 women presented with hepatitis E in labor. Condom balloon tamponade was inserted prophylactically in all hepatitis E virus (HEV) positive cases immediately after delivery of placenta along with vaginal packing, irrespective of amount of bleeding. Inspite of so many odds in the form of unscanned pregnancies, multiparity, multifetal gestation, abruption, intrauterine fetal death (IUFD), prolonged labor, deranged liver and coagulation profiles, anemia and thrombocytopenia, our study showed high effectiveness of prophylactic condom balloon tamponade by encountering only one case of PPH.

Conclusions: Prophylactic condom balloon tamponade insertion just after the removal of placenta is promising in averting PPH.

Keywords: Hepatitis E, Pregnancy, Postpartum hemorrhage, Condom balloon tamponade

\section{INTRODUCTION}

In pre-eclampsia, there is increased uteroplacental resistance and reduced fetal perfusion due to inadequate invasion of spiral arterioles by trophoblast cells. This causes impaired fetal growth and fetal hypoxia. Precelampsia contributes to $25 \%$ perinatal morbidity and mortality and optimal evaluation of fetus is necessary to ensure a good outcome. ${ }^{1}$ Ultrasonography is done to evaluate fetal well-being by biophysical profile and recently Doppler ultrasound has emerged as a vital tool for antenatal surveillance. As the fetoplacental unit develops, impedance in umbilical artery decreases with increased diastolic velocity. The normal umbilical artery waveform in last trimester shows low impedance and high diastolic flow with low pulsatility index (PI) and low resistive index (RI). In pregnancies complicated with pre-eclampsia and IUGR, umbilical blood flow reduces due to placental vascular resistance.

Hepatits $\mathrm{E}$ virus (HEV) is an emerging infectious agent causing acute viral hepatitis worldwide. ${ }^{1}$ Annually, there are an estimated 20 million $\mathrm{HEV}$ infections, 3.3 million 
symptomatic cases and 60,000 deaths worldwide. ${ }^{2,3}$ The disease is generally self-limiting in healthy individuals and causes chronic hepatitis in immune-compromised. Acute infection is generally mild and self-limited, having incubation period of 810 weeks with no chronic sequelae.

HEV infection in pregnancy is associated with great challenge due to high fatality. The fatality rate among the pregnant women who develop the disease may be as high as $15-20 \%$ mainly due to acute hepatic failure, deranged coagulation profile, renal dysfunction, intrauterine fetal death (IUFD) and postpartum hemorrhage (PPH). ${ }^{1}$ Although the mechanism of liver injury is not yet clear, it is possible that interplay of hormonal and immunologic changes during pregnancy along with high viral load of HEV, renders the women more vulnerable. ${ }^{5}$ Pregnant women with HEV infection and deranged coagulation profile makes it difficult for obstetrician to confront. Hence leading to delay in decision for termination of pregnancy even for obstetric indication.

Hemorrhage during third stage of labor is a matter of great concern in almost all pregnancies with jaundice. The bleeding is partly due to uterine atony but mostly due to deficiency of coagulation factors produced by the damaged liver. ${ }^{6}$ The incidence of postpartum hemorrhage in pregnancies with hepatitis e varies from $14-42 \%$ as reported by various authors. ${ }^{7,8}$ Management of labor in these women with acute liver injury makes it a real obstetric challenge as it restricts usage of most of the drugs leaving us with very few options to manage this jeopardy. Prophylactic insertion of uterine balloon tamponade along with active management of the third stage of labour (AMTSL) not only prevent primary PPH in these women, it also reduces the chance of further bleeding. Simultaneous use of injection tranexemic acid further gives reliable results.

The present study was conducted to study the effectiveness of intrauterine balloon tamponade in preventing PPH in pregnant women with acute hepatitis E infection.

\section{Aim}

The present study was conducted to study the effectiveness of condom balloon tamponade to prevent $\mathrm{PPH}$ in pregnant women with acute hepatitis $\mathrm{E}$ in labor.

\section{METHODS}

The present study is an interventional study, conducted in the department of obstetrics and gynecology, Pt. Jawaharlal Nehru Medical (JNM) College and associated Dr. Bhim Rao Ambedkar Memorial (BRAM) Hospital, Raipur, Chhattisgarh over period of two year from September 2018 to September 2020 during this period we witnessed epidemic of hepatitis $\mathrm{E}$ infection in our area.

Clearance to perform the study was taken by institutional review board and ethical committee. Preinformed consent was taken from all in labor acute hepatitis E positive cases regarding planned insertion of condom catheter prophylactically.

All acute hepatitis E cases in labor were admitted and details regarding demographic profile, clinical characteristics, laboratory investigations and maternal outcome were recorded in proforma. All cases in third stage of labour underwent AMTSL. Condom balloon tamponade was prepared with a Foley's catheter of size 2022 along with $20 \mathrm{ml}$ syringes and $500 \mathrm{ml}$ bottle of saline all were kept prehand in anticipation of PPH. It was inserted prophylactically in all HEV positive cases immediately after delivery of placenta along with vaginal packing and $1 \mathrm{gm}$ tranexamic acid, irrespective of amount of bleeding. Retained products of conception and genital tract trauma were excluded prior to its insertion. Blood loss of $>500 \mathrm{ml}$ in vaginal delivery and $>1000 \mathrm{ml}$ in cesarean delivery was taken as PPH, blood loss assessment was done by pictorial blood loss assessment charts while inflating the device, balloon tamponade was inflated with a volume of $300 \mathrm{ml}$, if bleeding persisted inflation was increased to additional $20 \mathrm{ml}$, arbitrary we set an upper limit of $500 \mathrm{ml}$ in case of atonicity. If the bleeding continued case was taken for surgical intervention of PPH. Results were measured in term of mean prophylactic cognitive behavioral therapy (CBT) volume and mean time interval for prophylactic CBT to hemostasis. Balloon tamponade was removed after 24 hours, and bleeding and vitals were constantly monitored. Blood products were transfused as per standard operating procedure (SOP) department. All the patients were kept in high dependency unit (HDU) and managed in collaboration with anesthetist and physician.

\section{Mean prophylactic CBT volume}

It is the amount of saline needed to inflate the CBT to achieve hemostasis.

\section{Mean time interval for prophylactic CBT to hemostasis}

It is the time from insertion of CBT to attainment of hemostasis.

\section{Inclusion criteria}

Our study population included 32 cases including all antenatal women with acute hepatitis E infection during pregnancy, who were in labor were admitted at Dr. BRAM Hospital and were studied during this period.

\section{Exclusion criteria}

Women with acute hepatitis E who were not in labor.

\section{Data analysis}

The data was entered into excel 2020 sheet and analyzed with statistical package for the social sciences (SPSS) 
version 20. Results were reported as mean, standard deviation and number percentage.

\section{RESULTS}

During the above-mentioned study period 32 antenatal women with hepatitis e infection were included, majority of the patient were of age group 20-25 years and maximum i.e. $90.6 \%$ were unbooked. SES there is linear increase in hepatitis E cases with decreasing SES, highest among lower class $65.7 \%$. Highest $(40.6 \%)$ incidence was among primipara. As all the laboring patients were included in present study out of them $68.7 \%$ were in latent phase and $31.2 \%$ were in active phase.

In laboratory investigations aspartate aminotransferase (AST) and alanine aminotransferase (ALT) levels shows a direct relation with severity of disease, level of $>500 \mathrm{IU} / 1$ was seen in majority cases i.e. $71 \%$ and $75 \%$ cases respectively. International normalised ratio (INR) is directly related to prognosis and occurrence of PPH among all cases $67.6 \%$ had INR $>1.5$.

Table 1: Demographic profile of the study subjects in the study population.

\begin{tabular}{|lcc|}
\hline Demographic feature & $\begin{array}{l}\text { Number } \\
\text { (n=32) }\end{array}$ & Percentage \\
\hline Age (in years) & & \\
\hline$<20$ & 01 & 3.1 \\
\hline $20-25$ & 20 & 62.5 \\
\hline $25-30$ & 10 & 31.2 \\
\hline$>30$ & 01 & 3.1 \\
\hline ANC care status & & \\
\hline Booked & 03 & 9.3 \\
\hline Un booked & 29 & 90.6 \\
\hline Residence status & & \\
\hline Rural & 07 & 21.8 \\
\hline Urban & 25 & 78.1 \\
\hline Socioecomic status (modified Kuppuswamy scale) \\
\hline Lower class & 21 & 65.6 \\
\hline Middle class & 06 & 18,7 \\
\hline Upper class & 05 & 15.6 \\
\hline Parity distribution & & \\
\hline Primi & 13 & 40.6 \\
\hline Gravida 2 & 11 & 34.3 \\
\hline Gravida 3 & 15.6 \\
\hline Gravida 4 & 05 & 6.2 \\
\hline Gravida 5 & 02 & 3.1 \\
\hline Phase of labor & 01 & \\
\hline Latent phase & & \\
\hline Active phase & & \\
\hline
\end{tabular}

$71.8 \%$ underwent vaginal delivery being the preferred mode of delivery in present study because of the additional risks associated with cesarean section. Instrumental delivery in the form of outlet forceps was applied in one patient due to early exhaustion and poor maternal bearing down. $94.3 \%$ cases underwent spontaneous labor while Induction of labor was done in 5 cases due to intrauterine fetal death.

Among 2 cases of hemorrhagic shock, one was antepartum haemorrhage (APH) third gravida with gestational age of 34 weeks presented in advanced labor with grade III hemorrhagic shock for which aggressive resuscitation was done. Patient delivered vaginally; prophylactic balloon tamponade insertion helped in averting PPH and other was in atonic PPH and could not be saved.

Out of 5 maternal deaths 4 were due to hepatic consequences of hepatitis e infection and one was unfortunately because of atonic PPH.

Table 2: Laboratory investigations.

\begin{tabular}{|c|c|c|}
\hline Etiology & $\begin{array}{l}\text { Number } \\
(n=32)\end{array}$ & Percentage \\
\hline \multicolumn{3}{|c|}{ S. bilirubin (mg/dl) } \\
\hline$<5$ & 03 & 9.3 \\
\hline $5-10$ & 17 & 53.1 \\
\hline $10-15$ & 08 & 25.0 \\
\hline$>15$ & 04 & 12.5 \\
\hline Mean & $9.3 \pm 4.7$ & \\
\hline \multicolumn{3}{|l|}{ AST (IU/I) } \\
\hline$<100$ & 01 & 3.1 \\
\hline $100-500$ & 08 & 25.0 \\
\hline $500-1000$ & 18 & 56.2 \\
\hline$>1000$ & 05 & 15.6 \\
\hline Mean & $646.8 \pm 379.3$ & \\
\hline \multicolumn{3}{|l|}{ ALT (IU/I) } \\
\hline$<100$ & 01 & 3.1 \\
\hline $100-500$ & 07 & 21.8 \\
\hline $500-1000$ & 17 & 53.1 \\
\hline$>1000$ & 07 & 21.8 \\
\hline Mean & $614.3 \pm 351.5$ & \\
\hline \multicolumn{3}{|l|}{ Platelet count } \\
\hline$<50,000$ & 03 & 9.3 \\
\hline $50,000-1,00,000$ & 02 & 6.2 \\
\hline 1 lac- $1,50,000$ & 02 & 6.2 \\
\hline$>1,50,000$ & 25 & 78.1 \\
\hline Mean & $162.3 \pm 109.9$ & \\
\hline \multicolumn{3}{|l|}{ INR } \\
\hline$<1.5$ & 10 & 32.3 \\
\hline$>1.5$ & 22 & 67.6 \\
\hline Mean & $1.61 \pm 0.4$ & \\
\hline \multicolumn{3}{|l|}{ Hb (gm\%) } \\
\hline$<4$ & 02 & 5.8 \\
\hline $4-6.9$ & 05 & 14.7 \\
\hline $7-8.9$ & 06 & 20.5 \\
\hline $9-10.9$ & 12 & 38.2 \\
\hline$>11$ & 07 & 23.5 \\
\hline Mean & $9.4 \pm 2.5$ & \\
\hline
\end{tabular}


Table 3: Labor details of the study subjects.

\begin{tabular}{|lll|}
\hline $\begin{array}{l}\text { Parameter } \\
\text { Type of pregnancy }\end{array}$ & Number & Percentage \\
\hline Single & 30 & 93.7 \\
\hline Multiple & 02 & 6.25 \\
\hline Gestational age & & \\
\hline Preterm & 22 & 68.7 \\
\hline Term & 10 & 31.2 \\
\hline Onset of labor & & \\
\hline Spontaneous & 27 & 84.3 \\
\hline Induced & 05 & 15.6 \\
\hline Mode of delivery & & \\
\hline Vaginal & 23 & 71.8 \\
\hline Instrumental & 01 & 3.1 \\
\hline LSCS & 08 & 25 \\
\hline
\end{tabular}

Table 4: Maternal outcome.

\begin{tabular}{|lll|}
\hline Parameter & Number & Percentage \\
\hline APH & 03 & 9.3 \\
\hline Prolonged labor & 05 & 15.6 \\
\hline Atonic PPH & 01 & 3.1 \\
\hline $\begin{array}{l}\text { Deranged coagulation } \\
\text { profile }\end{array}$ & 05 & 15.6 \\
\hline ARDS & 02 & 6.2 \\
\hline Hepatic encephalopathy & 06 & 18.7 \\
\hline Hepatorenal syndrome & 02 & 6.2 \\
\hline Fulminante hepatic failure & 06 & 18.7 \\
\hline Sepsis & 02 & 6.2 \\
\hline Hemorrhagic shock & 02 & 6.2 \\
\hline Discharge & 21 & 65.6 \\
\hline $\begin{array}{l}\text { Transferred to critical care } \\
\text { unit }\end{array}$ & 05 & 15.6 \\
\hline Maternal death & 06 & 18.7 \\
\hline
\end{tabular}

Table 5: Additional risk factors for $\mathrm{PPH}$ in the present study.

\begin{tabular}{|lll|}
\hline Parameter & $\begin{array}{l}\text { Number } \\
(\mathbf{n}=\mathbf{3 2})\end{array}$ & Percentage \\
\hline Unbooked & 29 & 90.6 \\
\hline Multiparity & 08 & 25 \\
\hline Multifetal gestation & 02 & 6.2 \\
\hline APH & 03 & 9.3 \\
\hline Intrauterine death & 05 & 15.6 \\
\hline Prolonged labor & 05 & 15.6 \\
\hline Anemia & 25 & 78.1 \\
\hline Thrombocytopenia & 07 & 20.8 \\
\hline S. bilirubin $>\mathbf{1 0}$ mg \% & 12 & 37.5 \\
\hline S. AST $>\mathbf{5 0 0}$ IU/l & 23 & 71.8 \\
\hline S. ALT $>\mathbf{5 0 0}$ IU/I & 24 & 74.9 \\
\hline INR $>\mathbf{1 . 5}$ & 22 & 67.6 \\
\hline
\end{tabular}

\section{DISCUSSION}

"If you can fill the unforgiving minute with sixty seconds, worth of distance run".

The above dictum can be used aptly in context of third stage of labor. This is indeed the stage of labor which if not managed carefully can lead to nightmare for obstetrician. PPH is one of the most fatal complications of this stage. Though every woman is at risk of PPH, presence of jaundice further adds to pitfall, as there is derangement of synthetic function of liver leading to deficiency of coagulation factors.

Coagulopathy is a well-known complication which occurs in acute viral hepatitis $\mathrm{E}$ in pregnancy. It further leads to potential for spontaneous bleeding and hemorrhagic complications mainly in the form of PPH. Management of labor in these women with acute liver injury makes it a real obstetric challenge as it restricts usage of most of the drugs and leave us with very few options to manage this jeopardy. Some or the other prophylactic measure to avert this situation would be the best measure. So, the present study was conducted to find out the effectiveness of prophylactic balloon tamponade and injection tranexamic acid in preventing PPH in women with hepatitis E in labor.

Most of the women in present study were of 20-25 years of age group $(61.7 \%)$. Our findings are consistent with the studies by Yadav et al and Shinde et al who also reported $\mathrm{HEV}$ infection frequently in the women of similar age group. ${ }^{9}$ This may be due to the fact that this is the most fertile period of age and early marriages, and childbirth are prevailing in this part of world. $90.6 \%$ of the cases were unbooked in the present study, which poses these women at higher risk of $\mathrm{PPH}$, as they were uninvestigated and nutritionally deprived.

Our study showed certain predisposing factors multiplicating the further risk if PPH. In the present review, $25 \%$ of women were multiparous while, in the study by Prasad et al. ${ }^{10} 18.1 \%$ of the subjects were of third and higher gravidity. Each successive labor carries a greater risk of PPH and women with repeated childbirth within short interval increases the risk of malnutrition and chronic iron deficiency anemia making them more vulnerable for PPH even with moderate amount of blood loss. Overdistention of uterus because of multiple pregnancy is also a predisposing factor for $\mathrm{PPH}$ as there is lack of retractile power, moreover there is large placental surface to bleed. $6.2 \%$ of women had multifetal gestation in the present study, in which one woman had triplet pregnancy our study constituted the largest group of women to have diagnosed the viral infection with multifetal pregnancy, Siddiqui and Rashid from Bangladesh reported $2.1 \%$ of the multifetal gestation in their study. Uterine exhaustion due to prolonged labor is a known risk factor for PPH. $13.5 \%$ of the patients had prolonged labor in the present review, severe liver damage 
in cases of viral hepatitis is culprit to early uterine exahaustion.

Anemia is always a known cause of PPH. Even with slight derangement in coagulation mechanism acts together with anemia to precipitate PPH. In our study, $78.1 \%$ of cases had anemia at presentation with $20.8 \%$ of them being severely anemic, so even slight blood loss in such cases lead to PPH whereas Yadav et al documented only 3.6\% of the cases with severe anemia in their study. ${ }^{8}$ These patients were managed by pre delivery blood transfusions, blood transfusions were made as per pre-delivery hemoglobin $(\mathrm{Hb})$ and standard operating protocol for blood transfusion in our department and further arrangements were made for delivery in anticipation.

"Nothing begets hemorrhage so much, as hemorrhage itself".

Morbidity in the form of coagulation profile, encephalopathy and fulminant hepatic failure is usually associated with hepatitis e cases. The presence of clot in utero interferes with retractile power of uterus and renders it atonic. $9.3 \%$ of the study subjects had abruption in the present study further worsening the coagulation profile. $15.6 \%$ of our patients had IUFD in utero exposing the women for coagulation failure and hemorrhage, all of them had INR above 1.5. Correction of deranged coagulation profile with FFP and cryoprecipitate was done as per standard protocols prior to delivery and in peripartum period.

Liver function tests indicate the degree of hepatocyte injury. Mean total serum bilirubin in the study subjects was $129.3 \pm 4.7$ with $37.5 \%$ of patients had serum bilirubin more than $10 \mathrm{mg} \%$ which indicates that these are the cases with more deranged synthetic function of liver, making them vulnerable for PPH whereas in the study by Yadav et al $40 \%$ of the women had serum bilirubin $>12 \mathrm{mg} \%$ and PPH seen in their study was $42 \% .^{8}$ In our study $71.8 \%$ of the study subjects had serum AST more than 500 IU/l, while $74.9 \%$ had serum ALT more than 500 IU/1 which suggests that these women were in advanced stage of the disease, exposing them at risk for $\mathrm{PPH}$.

Delivery is considered safe if INR is in normal range (<1.5) however this level is arbitrary based on small studies. Deranged coagulation profile grossly increases the chances of bleeding complications particularly PPH. 9.6\% of the study subjects had platelet count less than 50,000 in the present review, whereas $67.6 \%$ have INR above 1.5 . In the study by Yadav et al $56 \%$ cases had INR $>1.5$ which is comparable to present study, but PPH (42\%) and maternal mortality $(52 \%)$ was much higher in their study. Early management was our priority as there was an outbreak and prehand arrangements of blood products like FFP, platelets were made for these women. As per SOP of department, FFP was transfused in cases with INR $>1.5$, initial dose of FFP was $10-15 \mathrm{ml} / \mathrm{kg}$ body weight (3-4 units) stat dose followed by 2 units every eight hourly till INR is $<1.5$.
The preferred mode of delivery in a patient with jaundice with deranged liver function should be vaginal as there is not much consensus and study by various authors had stated vaginal route as the most common mode of delivery as decision for LSCS is difficult due to increased chances of morbidity and anesthetic complications. Majority of the study subjects in the present study also delivered vaginally (71.8\%), while LSCS had been done in $25 \%$ of the subjects, for obstetric indications only.

In pregnant women with hepatis $\mathrm{E}$ infection effect of coagulopathy and factors influencing the occurrence of $\mathrm{PPH}$ together put the obstetrician in a very indecisive and difficult situation. Intrauterine condom balloon tamponade has a known beneficial effect in controlling PPH even with hepatic failure, deranged coagulation profile and hepatic failure. AMTSL was done in all the cases, followed by insertion of prophylactic CBT just after removal of placenta, irrespective of the amount of bleeding. Mean prophylactic CBT volume was $250 \mathrm{cc}$ (95\% CI 220-300 cc) and mean time interval for prophylactic CBT to hemostasis was $12 \mathrm{~min}$ (95\% CI 6-18 min). The rate of PPH declined significantly and it also everted invasive surgical procedures. Siddiqui and Rashid also inserted prophylactic condom tamponade and documented its effectiveness in preventing $\mathrm{PPH}^{6}$

Maternal mortality rate in the present study was $17.6 \%$ which is comparable to the study by Shreshtha et al $(19.3 \%)$ and Rasheeda et al $(20 \%) .{ }^{12,13}$ Khurro et al (55\%), Patra et al $(41 \%)$, Yadav et al $(29.4 \%)$ and Lewis et al $(52.6 \%)$ had much higher maternal mortality rates. ${ }^{7,8,14,15}$ All six maternal deaths had fulminant hepatic failure. Two of the patients had associated hepatorenal syndrome among them one patient went into atonic PPH even after prophylactic insertion of balloon tamponade for which exploratory laprotomy was done, unfortunately patient died on sixth post-operative day due to fulminate hepatic failure and hepatic encephalopathy. No case underwent traumatic PPH. Inspite of so many odds in the form of unscanned pregnancies, multiparity, multifetal gestation, abruption, IUFD, prolonged labor, deranged liver and coagulation profiles, anemia and thrombocytopenia, only one woman suffered PPH in the present study.

\section{Limitations}

Limitations of the study needs more multicentric studies in our area for generalization of results

\section{CONCLUSION}

Prevention is always better than cure; an obstetrician should always be visionary in managing labor and PPH in high-risk pregnancy such as hepatitis E. It is the situation which makes the parturient more prone for PPH. Once PPH occurs in this situation, it is very difficult to manage it as it leads to further derangement of coagulation profile and leaves the obstetrician with only handful of drugs to handle this catastrophe. So, prophylactic condom balloon 
tamponade insertion just after the removal of placenta is promising in averting PPH. So, systematic, early and timely approach towards management in the form of prophylactic condom balloon tamponade can bring a ray of hope in such grim situation.

Funding: No funding sources

Conflict of interest: None declared

Ethical approval: The study was approved by the Institutional Ethics Committee

\section{REFERENCES}

1. Rein DB, Stevens GA, Theaker J, Wittenborn JS, Wiersma ST. The global burden of hepatitis E virus genotypes 117 and 2 in 2005. Hepatology. 2012;55(4):988-97.

2. Nimgaonkar I, Ding Q, Schwartz RE, Ploss A. Hepatitis E virus: advances and challenges. Nat Rev Gastroenterol Hepatol. 2018;15:96-110.

3. World Health Organization. Hepatitis E. Available at: https://www.who.int/en/news-

room/factsheets/detail/hepatitis-e. Accessed on 08 July 2019.

4. Goumba CM, Yandoko-Nakouné ER, Komas NP. A fatal case of acute hepatitis $\mathrm{E}$ among pregnant women, Central African Republic. BMC Res Notes. 2010;3:103.

5. Fiore S, Savasi V. Treatment of viral hepatitis in pregnancy. Expert Opin Pharmacother. 2009;10(17):2801-9.

6. Siddiqui M, Rashid M. Balloon Tamponade to prevent primary PPH in Jaundice- A Prospective Study. J Bangl Coll Physic Surg. 2008;26(1):22-5.

7. Patra S, Kumar A, Trivedi SS, Puri M, Sarin SK. Maternal and fetal outcomes in pregnant women with acute 35 hepatitis E virus infection. Ann Intern Med. 2007;147(1):28-33.

8. Yadav S, Shirodker S, Kshirsagar S. Maternal and fetal outcome in pregnancy with hepatitis E virus infection. Int J Reprod Contracept Obstet Gynecol. 2016;5:3482-90.

9. Shinde N, Patil T, Deshpande A, Gulhane R, Patil M, Bansod Y. Clinical profile, maternal and fetal outcomes of 42 acute hepatitis e in pregnancy. Ann Med Health Sci Res. 2014;4(2):133.

10. Prasad GS, Prasad S, Bhupali A, Patil AN, Parashar K. A Study of Hepatitis E in Pregnancy: Maternal and Fetal Outcome. J Obstet Gynaecol India. 2016;66(1):18-23.

11. Puri M, Patra S, Singh P, Malhotra N, Trivedi SS, Sharma S, Kumar A, Sarin SK. Factors influencing occurrence of postpartum haemorrhage in pregnant women with hepatitis $\mathrm{E}$ infection and deranged coagulation profile. Obstet Med. 2011;4(3):108-12.

12. Shrestha P, Bhandari D, Sharma D, Bhandari BP. A study of viral hepatitis during pregnancy in Nepal Medical College Teaching Hospital. Nepal Med Coll J. 2009;11:192-4.

13. Sultana R, Humayun S. Fetomaternal outcome in acute hepatitis e. J Coll Physicians Surg Pak. 2014;24(2):127-30.

14. Khuroo MS, Kamili S, Jameel S. Vertical transmission of hepatitis $\mathrm{E}$ virus. Lancet. 1995;345:1025-6.

Cite this article as: Thakur N, Kishore R, Tuwani M. Sooner than later: a little effort may avert postpartum haemorrhage in patients with acute hepatitis E. Int J Reprod Contracept Obstet Gynecol 2021;10:3764-9. 